\title{
Vaccine and Needle-Free Vaccination Delivery System
}

\author{
Tianyu Ren, Xiliang Wang, Shaogeng Zhang and Peng Hui Yang*
}

302 Military Hospital; Beijing Institute of Microbiology and Epidemiology, Beijing, 100039, China

\begin{abstract}
Needle-free injection delivery system is a new method use a unique profile to deliver vaccine to the proper tissue depth for injection. The shift from needle-based to needle-free immunization is also catalyzed, in part, by the realization that skin, which can increase vaccine immunogenicity, is ideal target for vaccine delivery. As a promising delivery of vaccines system, it has the potential to decrease the dose of vaccine antigen, enhance immune response and may furthermore help to reduce costs.
\end{abstract}

Keywords: Immunization; Skin; Jet injection; Immunogenicity

\section{Introduction}

Needles and syringes are the most commonly used immunization procedures, associated with avoidance and phobic behaviors in a large proportion of people [1]. Needle phobia makes immunizations stressful, moreover needle-stick injury [2,3], improper and unsafe use, such as re-use of needle or syringe cause transmit blood-borne pathogens lead to large number of HBV, HCV and HIV cases, are serious problems in all countries [4]. However, the development of needle-free injection methods has now been identified as an important goal to prompt global health care [5]. It is a highly flexible technology holds much potential using various techniques, including an instrument delivers a high speed liquid vaccine stream into skin or target regions. In the future, this new vaccination technology may make needles redundant [6].

Skin is an interest target and an alternative site for vaccine delivery $[7,8]$, not only because of the ease of access, but also its unique immunological properties. Skin vaccine methods have been tested in many clinical trials, such as rabies [9], hepatitis B [10] and influenza vaccines [11]. In the case of the influenza vaccine, Richard [12] compared the immunogenicity of intradermal immunization with standard intramuscular immunization. They reported that the viability of a dose-sparing strategy involving intradermal injection with a fraction of the intramuscular dose, one fifth of a standard intramuscular dose of antigen is equivalent or comparable to the full dose [12]. It has both cellular and humoral immune system components. Thus far, as the gatekeeper and barrier of the immune systems, it efficiently elicits both innate and adaptive immune responses and improved long term protection [13]. The central group of immune cells involved innate immune response is dendritic leukocytes, Langerhans cells and dendritic cells [14-17]. All of them as members of the family of antigenpresenting cells act as both the first line to interact with incoming pathogen, and play a pivotal role as messengers that are able to alert adaptive immune response against pathogens and antigens [18]. Since naive $T$ and $B$ cells rely on the innate immune system to sense infectious events. The antigen-presenting cells capture and process the antigen entering the skin, and re-express part of it as peptide/MHC complex on the surface are also profoundly affected by danger signals or danger signal-induced cytokine [19]. In a word, deliver vaccine directly to the APCs can enhance the vaccine potency via strategies that modify the properties of antigen-presenting cells. On the contrast, when the use of needle based injections of vaccine deliver the antigen to the muscle region is thought to be a limited space that contains little numbers of antigen-presenting cells and stimulate weak response.

According to the above definition, the characteristics, structural and cellular make-up enable skin is quite significant for vaccination. Nonetheless, it cannot be effectively accessed by conventional needles due to the lack of simple and reliable technologies. Furthermore, the fact that only part of volumes of fluid vaccine can be injected precisely. As the possible routes for immunization, the technologies for needlefree injection delivery system administration of vaccines through the skin, is suitable for all ages and both genders.

Needle-free injection delivery system is a new method use a unique profile to deliver vaccine to the proper tissue depth using driving force for injection [20]. When compared with needles, the methods showed multiple benefits [21]. It can be less painful, so it would increase acceptability and reduce needle stick injuries would enhance occupational safety for minimally trained personnel. This could be particularly significant in the future should it become necessary to consider how they might conduct mass immunization campaigns rapidly. In order to deal with the threat, needle-free technologies, for example a single-use nozzle jet injector that can reduce the risk of splash back of blood and reduce the dose of vaccine, the factors become necessary when vaccine shortage such as a pandemic influenza or bioterrorism emergency, also could simplify immunization schedules. However, some studies have reported that this technology have been associated with more frequent local-reaction, including bruising, redness, swelling of the injection site. In addition, improper use of the needle-free injection devise can cause the vaccine are not able to accurately inject into the skin, or can lead to the immediate pain.

Indeed, several publications investigating genetic vaccines have demonstrated that route via skin of administration results in typical higher efficacy. More recently, vaccine dose-sparing by delivery using needle-free technologies is well established in clinical practice for Inactivated Poliovirus Vaccine (IPV). This evaluation well document that vaccinating infants with a single fractional dose of IPV can induce priming and sero-conversion in more than $90 \%$ of immunized infants [22]. Moreover, we know that DNA vaccine immunogenicity has

*Corresponding author: Peng Hui Yang, 302 Military Hospital, Beijing Institute of Microbiology and Epidemiology, Beijing, 100039, China, Tel: +86-01066933336; E-mail: ypenghuiamms@hotmail.com

Received September 04, 2014; Accepted September 26, 2014; Published October 03, 2014

Citation: Ren T, Wang X, Yang PH (2014) Vaccine and Needle-Free Vaccination Delivery System. J Microb Biochem Technol 6: 359-360. doi:10.4172/19485948.1000168

Copyright: (c) 2014 Ren T, et al. This is an open-access article distributed under the terms of the Creative Commons Attribution License, which permits unrestricted use, distribution, and reproduction in any medium, provided the original author and source are credited 
Citation: Ren T, Wang X, Yang PH (2014) Vaccine and Needle-Free Vaccination Delivery System. J Microb Biochem Technol 6: 359-360. doi:10.4172/1948-5948.1000168

been limited by inefficient delivery [23]. Needle-free devices have also successfully delivered DNA vaccines in clinical trials pointed that this is a promising method for stimulating gene expression and immune response owing to the presence of Langerhans cells [24,25].

Vaccines are one of the most cost-effective preventive methods for controlling the infectious diseases. And the needle-free injection system can propel liquid vaccine (live or nonliving) into the skin, due to the kinetic energy of a high velocity vaccine jet. The development of effective strategies for skin vaccination without the 'sharps', immunization practice would become safer, more economical and more suitable would revolutionize immune. Cost of immunization also is a critical factor when we need to accept a new method. Cutting the dose cannot decrease the response, it was thought to be a reasonable approach if vaccine happened to be in short supply and make routine vaccination affordable for use in all countries [22]. It is hoped that this new method will lower the economic burden and ease the logistical burdens of immunization programs [26]. In addition to scientific and immunological concerns, it has the potential to improve both the logistics and immunology of vaccine. The skin represents an excellent site for vaccine inoculation due to its natural role and the high local frequency of antigen presenting cells that serve to amplify immune response. Advantages in needle-free injection delivery system have attracted lots of researchers and businesses to the field of vaccine development. Overall, this system can be acted as a technological innovation that would remove a critical barrier to solving an important health problem in worlds.

\section{References}

1. Andrews GJ (2011) 'I had to go to the hospital and it was freaking me out': needle phobic encounter space. Health Place 17: 875-884.

2. Akeem BO, Abimbola A, Idowu AC (2011) Needle stick injury pattern among health workers in primary health care facilities in Ilorin, Nigeria. Academic Research International 1: 419-427.

3. Duff AJ, Gaskell SL, Jacobs K, Houghton JM (2012) Management of distressing procedures in children and young people: time to adhere to the guidelines. Arch Dis Child 97: 1-4

4. Kermode M (2004) Unsafe injections in low-income country health settings: need for injection safety promotion to prevent the spread of blood-borne viruses. Health Promot Int 19: 95-103.

5. Stahl-Hennig C, Kuate S, Franz M, Suh YS, Stoiber H, et al. (2007) Atraumatic oral spray immunization with replication-deficient viral vector vaccines. J Virol 81: $13180-13190$.

6. Senior K (2011) New vaccination technologies that make needles redundant Lancet Infect Dis 11: 16-17.

7. Holmgren J, Czerkinsky C (2005) Mucosal immunity and vaccines. Nat Med 11: S45-53.

8. Kupper TS, Fuhlbrigge RC (2004) Immune surveillance in the skin: mechanisms and clinical consequences. Nat Rev Immunol 4: 211-222.

9. Vien NC, Feroldi E, Lang J (2008) Long-term anti-rabies antibody persistence following intramuscular or low-dose intradermal vaccination of young Vietnamese children. Trans R Soc Trop Med Hyg 102: 294-296.

10. Charest AF, McDougall J, Goldstein MB (2000) A randomized comparison of intradermal and intramuscular vaccination against hepatitis $B$ virus in incident chronic hemodialysis patients. Am J Kidney Dis 36: 976-982.

11. Combadière B, Vogt A, Mahé B, Costagliola D, Hadam S, et al. (2010) Preferential amplification of CD8 effector-T cells after transcutaneous application of an inactivated influenza vaccine: a randomized phase I trial. PLoS One 5: e10818.

12. Kenney RT, Frech SA, Muenz LR, Villar CP, Glenn GM (2004) Dose sparing with intradermal injection of influenza vaccine. N Engl J Med 351: 2295-2301.

13. Sullivan SP, Koutsonanos DG, Del Pilar Martin M, Lee JW, Zarnitsyn V, et al.
(2010) Dissolving polymer microneedle patches for influenza vaccination. Nat Med 16: 915-920.

14. Koutsonanos DG, del Pilar Martin M, Zarnitsyn VG, Jacob J, Prausnitz MR, et al. (2011) Serological memory and long-term protection to novel H1N1 influenza virus after skin vaccination. J Infect Dis 204: 582-591.

15. Henri S, Guilliams M, Poulin LF, Tamoutounour S, Ardouin L, et al. (2010) Disentangling the complexity of the skin dendritic cell network. Immunol Cell Biol 88: 366-375.

16. Romani N, Clausen BE, Stoitzner P (2010) Langerhans cells and more: langerin-expressing dendritic cell subsets in the skin. Immunol Rev 234: 120 141.

17. Nestle FO, Di Meglio P, Qin JZ, Nickoloff BJ (2009) Skin immune sentinels in health and disease. Nat Rev Immunol 9: 679-691.

18. Merad M, Ginhoux F, Collin M (2008) Origin, homeostasis and function of Langerhans cells and other langerin-expressing dendritic cells. Nat Rev Immunol 8: 935-947.

19. Koutsonanos DG, del Pilar Martin M, Zarnitsyn VG, Sullivan SP, Compans RW, et al. (2009) Transdermal influenza immunization with vaccine-coated microneedle arrays. PLoS One 4: e4773.

20. Mitragotri S (2005) Immunization without needles. Nat Rev Immunol 5: 905 916.

21. Prausnitz MR, Langer $R$ (2008) Transdermal drug delivery. Nat Biotechnol 26 1261-1268.

22. Resik S, Tejeda A, Sutter RW, Diaz M, Sarmiento L, et al. (2013) Priming after a fractional dose of inactivated poliovirus vaccine. N Engl J Med 368: 416-424

23. Graham BS, Enama ME, Nason MC, Gordon IJ, Peel SA, et al. (2013) DNA vaccine delivered by a needle-free injection device improves potency of priming for antibody and CD8+ T-cell responses after rAd5 boost in a randomized clinical trial. PLoS One 8: e59340.

24. Roy MJ, Wu MS, Barr LJ, Fuller JT, Tussey LG, et al. (2000) Induction of antigen-specific CD8+ $T$ cells, $T$ helper cells, and protective levels of antibody in humans by particle-mediated administration of a hepatitis B virus DNA vaccine. Vaccine 19: 764-778.

25. Bråve A, Ljungberg K, Boberg A, Rollman E, Isaguliants M, et al. (2005) Multigene/multisubtype HIV-1 vaccine induces potent cellular and humoral immune responses by needle-free intradermal delivery. Mol Ther 12: 1197 1205

26. Ekwueme DU, Weniger BG, Chen RT (2002) Model-based estimates of risks of disease transmission and economic costs of seven injection devices in subSaharan Africa. Bull World Health Organ 80: 859-870. 